\title{
Milena Jovanović
}

\section{Klasična filologija v Srbiji 1944-1945: primer Veselina Čajkanovića}

Obdobje od konca druge svetovne vojne do razpada Jugoslavije ${ }^{1}$ lahko razdelimo na dve fazi: titoizem do maršalove smrti leta $1980^{2}$ in posttitoizem od leta 1980 naprej. Leti 1944 in 1945 sta minili v znamenju najokrutnejšega »rdečega terorja « [crveni teror] in »čistk«. V tem času se je komunistom ponudila lepa priložnost, da svoje politične nasprotnike odstranijo pod krinko boja proti zavojevalskim silam in njihovim sodelavcem. ${ }^{3}$ Za Tita je bila bistvenega pomena prevlada nad njegovim glavnim sovražnikom - mestnimi elitami. Intelektualci so bili še posebej osovraženi, saj so posedovali znanje; oblast lahko "zapleni«, »razlasti« in "nacionalizira« premoženje, nihče pa ne more odstraniti znanja in intelektualci so bili ena družbenih skupin, ki so postale tarča Titovih partizanov. Treba je poudariti, da se Titovo gibanje med drugo svetovno vojno v Srbiji ni ukoreninilo. ${ }^{4}$

Titova politična strategija je temeljila na dejavnem boju proti okupatorju, ki se ni oziral na izgubo življenj; v tem je prepoznal najučinkovitejši način, da ga zavezniki priznajo kot voditelja. Strategija se je izkazala za uspešno in zavezniki so Titu priznali voditeljske sposobnosti v jugoslovanskem protifašističnem boju, čeprav je ta boj hkrati izkoristil za državljansko

1 Obdobje titoizma je imelo več faz. Obdobje med letoma 1945-1948 in 1948-1953 je zaznamoval odnos s Sovjetsko zvezo; najprej »boj« za Sovjete, nato »boj « proti njim. Sledil je »boj« za »samoupravljanje«, »boj« proti »liberalizmu«, »boj« proti »nacionalizmu« in tako dalje. Vse te faze so imele v imenu pro ali contra; sledile so jim ustrezne spremembe v terminologiji.

2 Po zavezniškem bombardiranju 6. aprila 1944 so Beograd 20. oktobra 1944 »osvobodili« komunistični partizani, skupaj z Rdečo armado. To je bil začetek represije, kasneje poimenovane tudi »nova okupacija« ali »rdeči teror«.

3 Represija proti »notranjim sovražnikom«, »odporu« in tako dalje.

4 Večina prebivalcev, zlasti pa večina mestnih intelektualcev, je ostala na strani kralja Petra II. Karadjordjevića in poveljnika Jugoslovanske vojske v domovini (JVvD) Dragoslava Mihailovića. Položaj kmečkega prebivalstva je bil bolj zapleten. Zaradi tega se je jedro odpora proti sovražnim silam leta 1941 preneslo v Bosno in Hercegovino in Črno goro. 
vojno z enim samim ciljem - pridobiti politično moč. Srbijo so osvobodili leta 1944, nekaj mesecev pred ostalimi republikami. Nemudoma je prišlo do množičnega pomora političnih nasprotnikov, izpeljanega pod krinko boja proti fašističnim sovražnikom in njihovim sodelavcem, ne glede na to, ali so dejansko obstajali ali ne. ${ }^{5} \mathrm{~V}$ tem obdobju so bili številni intelektualci obtoženi in obsojeni, mnogi so preprosto izginili, ne da bi bili deležni vsaj formalnega sojenja.

Po krutem obdobju 1944-1945 so sojenja v Srbiji začela dobivati nekoliko bolj zakonito podobo, vsaj v svoji novonastali formalnosti. Vojaških sodišč ni bilo več, vlada je začela ustanavljati okrožna sodišča. Obstajala so tudi tako imenovana »častna razsodišča».

\section{VESELIN ČAJKANOVIĆ}

Veselin Čajkanović (1881-1946), profesor na Filozofski fakulteti Univerze v Beogradu, ki je užival spoštovanje svojih kolegov, ${ }^{6}$ je bil eden od žrtev Častnega razsodišča na Univerzi v Beogradu. Bil je dijak najstarejše beograjske gimnazije [Prva beogradska gimnazija], po koncu katere je študiral klasično filologijo na beograjski Veliki šoli [Velika škola], ki se je leta 1905 preoblikovala v Univerzo v Beogradu. Po diplomi leta 1903 je poslušal predavanja na univerzah v Leipzigu in Münchnu (1903-1907), kjer si je pridobil doktorski naziv.? Leta 1908 je postal predavatelj latinščine na Filozofski fakulteti Univerze v Beogradu. Sodeloval je v obeh balkanskih vojnah ter je v Bizerti ustanovil tiskarno in urejal časopis za bolne, ranjene in pohabljene vojake. Sledila je prva svetovna vojna in leta 1915 je s srbsko vojsko potoval skozi Albanijo. Umik iz Albanije, med katerim so morali izčrpani, do kosti prezebli in sestradani vojaki prečkati zasnežene 2500 metrov visoke gore, se je izkazal za skrajno težavnega. Po vojni je Čajkanović leta 1919 kot profesor latinščine postal predstojnik Katedre za klasično filologijo in rimsko književnost; obenem je na Teološki fakulteti poučeval primerjalno zgodovino religije. Leta 1922 je postal član Srbske kraljeve akademije znanosti in bil nato $\mathrm{v}$ tridesetih letih večkrat izvoljen za dekana Filozofske fakultete. ${ }^{8}$

Njegovo znanstveno delo je obsegalo tri področja: kulturno dediščino, zgodovino religij, zlasti predkrščansko religijo in srbsko bajeslovje, ter klasič-

5 "Sovražnik ljudstva« je lahko postal vsak; ta praksa se je začela v Srbiji in se je nato leta 1945 razširila med druge jugoslovanske narode.

6 Biografske podrobnosti opisuje Marija Vranić-Ignačević, Veselin Čajkanović 1881-1946: katalog izložbe (Beograd: Univerzitetska biblioteka, 2006).

7 Veselin Čajkanović, „Quaestionum paroemiographicarum capita selecta, dissertatio inauguralis quam ad summos in philosophia honores ab amplissimo philosophorum ordine sectionis I, in Universitate Ludovico-Maximilianea Monacensi rite impetrandos« (doktorska disertacija, Univerza v Münchnu, 1908).

8 Glej spodaj, dokument št. 3, pogovor z Nikolo Čajkanovićem, 5. marec 2002. 
no filologijo, ki je bila njegov osrednji raziskovalni interes. Med poučevanjem na univerzi je Čajkanović objavil več strokovnih klasičnofiloloških razprav, ${ }^{9}$ pa tudi vrsto publikacij, s katerimi je skušal antiko približati mlajšim generacijam. ${ }^{10} \mathrm{~V}$ letih 1927 in 1928 je izdal tudi štiri latinske čitanke za višje razrede gimnazije, leta 1932 Pregled zgodovine rimske književnosti, leta 1940 Florilegium Latinum in usum scholarum. Njegova učna metoda je v grških in latinskih avtorjih iskala predvsem intelektualni vzor; lahko bi rekli, da je v Tacitu in Plutarhu videl osnovo za vse izobraževanje.

Eno od področij njegovega zanimanja so bili tudi grški in rimski viri za basni Dositeja Obradovića. Čajkanovićeve študije o kulturni dediščini so ga privedle do novega raziskovalnega področja - srbskih predkrščanskih verovanj. V svoji prvi večji razpravi Bog ima volnene noge in železne roke [U Boga su vunene noge, a gvozdene ruke], dokončani leta 1914, je trdil, da se stare predstave skozi čas niso izgubile, temveč so se prilagodile novim okoliščinam in potrebam. Zaradi svojega znanja grščine in latinščine ter več sodobnih jezikov je Čajkanović lahko uporabljal primerjalno metodo, s katero je rekonstruiral najstarejša prepričanja med ljudstvom. ${ }^{11}$ Njegovo morda najvidnejše delo na tem področju je razprava $O$ srbskem vrhovnem bogu [O srpskom vrhovnom bogu], ki je izšla leta $1941 \mathrm{v}$ dveh izdajah.

Začenši z obdobjem sredi tridesetih let 20. stoletja so kot humaniora ${ }^{12}$ iz helenskih študij izšle balkanološke študije. Klasično izobraženi filologi so se zavedali pomembnosti kritičnega raziskovanja virov, pa tudi etimologije, skladnje in semantike. ${ }^{13}$ Veselin Čajkanović je bil predhodnik te nove znanstvene metode, saj je starodavno religijo in srbsko bajeslovje raziskoval z multidisciplinarnega stališča, $\mathrm{z}$ uporabo primerjalne, filološke in historične analize. Leta 1934 so v Beogradu ustanovili Inštitut za študije Balkana, ${ }^{14}$ a ga je med drugo svetovno vojno okupator zaprl. ${ }^{15}$

9 Par naslovov: »Vergilij in njegovi sodobniki« (1930), »De nucibus in Romanorum nuptiis usurpatis« (1937).

10 Latinsko izročilo na tem območju je bilo v primerjavi z državami zahodne Evrope skromno. Vidna izjema je bila Vojvodina, kjer je bila latinščina bolj prisotna. Prepad med srbskimi intelektualci, ki so se izobraževali na evropskih univerzah, ter večino prebivalstva, ki je bila nepismena, je bil skoraj nepremostljiv; slednja je leta 1866 znašala 96 odstotkov, med vojnama pa 80 odstotkov, kar je v primerjavi s 27 odstotki v Beogradu naravnost pretresljivo.

11 Leta 1994, dolgo po smrti Veselina Čajkanovića, sta izšli dve njegovi pomembni deli: „Stara srbska religija in mitologija «ter "Slovar srbskih narodnih verovanj o rastlinah«.

12 Študij klasične filologije sodi na beograjski univerzi med humaniora in vsebuje klasično grščino in latinščino, književnosti obeh jezikov, bizantinske študije, balkanske študije, arheologijo in staro zgodovino.

13 Poudarjali so pomembnost arhetipov v ustvarjalnem postopku in kazali na prvine mita ter magije v umetniškem izrazu; metodo je vpeljal Milan Budimir (1891-1975). Obdobje med letoma 1920 in 1975 velja za nekakšno zlato dobo klasične filologije na beograjski univerzi.

14 Klasična filologa Milan Budimir in Petar Skok sta leta 1934 uredila Revue internationale des études balkaniques $\mathrm{v}$ štirih zvezkih, $\mathrm{v}$ času, ko je bil v Beogradu ustanovljen Inštitut za študije Balkana.

15 Ponovno vzpostavljen leta 1969 kot Inštitut za balkanske študije. 


\section{VOJNA}

Veselina Čajkanovića so med vojno imenovali za dekana Filozofske fakultete, baje proti njegovi volji. Dejstvo, da je bil med vojno na tem položaju, so povojne oblasti štele kot dokaz, da je bil sam eden izmed tvorcev tako imenovanega srbskega kulturnega načrta, ${ }^{16}$ kar naj bi pomenilo njegovo kolaboracijo s sovražnikom. V prvih letih rdečega terorja so krivdo raje domnevali kot dokazovali; in izdali so na tisoče obtožb. Čajkanovićev prestopek je bil v očeh novega režima trojen. Bil je intelektualec, njegovo področje raziskovanja sta bili religija in mitologija, med okupacijo pa je zasedal vpliven položaj. Kot je pri političnih procesih običajno, so bili »dokazi« ponarejeni ali izmišljeni, ne glede na njihovo logično ali sodno veljavo. Pri Čajkanoviću je režim za nominalni dokaz njegove krivde uporabil kar medvojni srbski kulturni program, takoimenovani »srbski civilni načrt«. To je bil razlog, da so ga leta 1945 izključili iz univerze in mu odvzeli »državljanske pravice« - tako pokojnino kot tudi volilno pravico. Državna komisija za preiskovanje zločinov okupatorjev in njihovih sodelavcev [Državna komisija za ispitavanje zločina okupatora $i$ njihovih pomagača] ga je obtožila nič manj kot vojnih zločinov — "poskusa širjenja fašizma med srbskim ljudstvom preko srbskega civilnega načrta, $\mathrm{v}$ imenu okupatorjevih sil«.

Tej kratki uvodni predstavitvi sledi nekaj dokumentov, ki danes govorijo sami zase. Medtem ko v nekaterih delih načrta, denimo v »biološkem sektorju«, dejansko naletimo na evgenično intonirane izraze, ki izdajajo izrazito problematično naravo dela evropske in ameriške znanosti pred drugo svetovno vojno, je v silno splošnih Čajkanovićevih razmišljanjih o položaju klasične filologije težko najti znake kaznivega dejanja.

\section{Dokumenti}

\section{DOKUMENT ŠT. 1}

Primer Veselina Čajkanovića

Arhiv Jugoslavije, Beograd, [april] 1945, fond 110, mapa 85-758.

Čajkanović, Veselin

Primer poslan javnemu tožilcu mesta Beograd 2540/45

Federativna republika Jugoslavija, mapa št. 760

Državna komisija za ugotavljanje zločinov okupatorjev in njihovih sodelavcev

Odločba o ugotavljanju zločinov okupatorjev in njihovih sodelavcev

16 Glej dokumenta št. 2 in 2 a. 
Storilec

Ime in priimek: dr. Veselin Čajkanović

Približna starost:

Narodnost: srbska

Enota, uradni položaj, čin: dekan Filozofske fakultete med okupacijo

Zadnji kraj bivališča: Beograd

Drugi osebni podatki:

Žrtve zločina (oškodovane osebe):

(z osebnimi podatki)

Kratek opis in oznaka zločina: prizadevanje za širjenje fašizma med srbskim ljudstvom v korist okupatorja prek vsiljenega srbskega civilnega načrta.

Dokazi:

izhodišča za Državni učni načrt znotraj srbskega civilnega načrta, inv. št. 1776 - I

načini srbske samouprave; razprave o srbskem civilnem načrtu, inv. št. 1776 - II

predpriprave za srbski civilni načrt, inv. št. 1776 - III

poročila profesorjev o srbskem civilnem načrtu, inv. št. 1776 - IV

Podrobnosti zločina:

Storilec, kraj, čas, način in sredstva izvedbe zločina, žrtve, škoda:

Dr. Veselin Čajkanović, dekan Filozofske fakultete med okupacijo Beograda, je predstavljal univerzo kot član svetovalnega odbora Ministrstva za šolstvo in vero v zadevi srbskega civilnega načrta, katerega začetnik in prireditelj je bil Vladimir Velmar-Janković, pomočnik ministra za šolstvo in vero. Glej odločbo o ugotavljanju zločinov Vladimirja Velmar-Jankovića, mapa št. 757.

Škoda:

Za kakšno škodo gre? - Vrednost v predvojnih dinarjih.

Sostorilci:

1. Velibor Jonić 758, minister za šolstvo in vero; 2. Vladimir Velmar-Janković 757, pomočnik ministra za šolstvo in vero; 3. dr. Nikola Popović 759, rektor Univerze; 4. dr. Radoslav Grujić 761, dekan Teološke fakultete; 5. dr. Branko Popović 762, dekan Tehniške fakultete; 6. dr. Mihailo Gradojević 763, dekan Fakultete za kmetijstvo; 7. dr. Nikola Radojčić 764, univerzitetni profesor; 8. Milosav Vasiljević, inženir 765, univerzitetni profesor; 9. dr. Dušan Popović, univerzitetni profesor.

Opomba

Primer poslan javnemu tožilcu mesta Beograd, dokument št. 2540/45.

Predsednik:

[podpis nečitljiv]
Sekretar:

[podpis nečitljiv] 


\section{DOKUMENT ŠT. 2}

Arhiv Jugoslavije, Beograd, fond 110, mapa 551

srbski civilni načrt [1942]

Fond 110; mapa 551-180, inv. št. 1776.

Klasična filologija

fond 110, mapa 551-184

Dr. Veselin Čajkanović

Vsi naši klasični filologi so izbirali posebno področje raziskovanja in teme, ki so $\mathrm{v}$ interesu nacionalno pomembnih raziskav, ter so poskušali ohraniti tesne stike s temi raziskavami. Bili so vidni sodelavci vseh revij, ki so gojile nacionalno pomembne raziskave. Tudi ena izmed revij s področja klasične filologije, Starinar, je imela v programu nacionalno pomembne teme. Knjižnica seminarjev za klasično filologijo in antično zgodovino ne zadostuje za znanstveno delo. Obstaja Društvo prijateljev klasičnih študij. Potrebni so učbeniki grške književnosti in antične zgodovine, srbsko-latinski in grškosrbski slovar ter slovar grške, rimske in orientalske antike. Tesne stike z nacionalno pomembnimi raziskavami je treba ohraniti.

Osebje iz kroga klasičnih filologov bi morali rekrutirati za bizantologijo, zgodovino religije, ljudsko slovstvo, etnografijo, balkanske študije. Želeti bi si bilo, da bi latinščina ponovno vzpostavila svoj položaj v gimnazijah. Obstaja velika potreba po tem, da klasični študiji dobijo ustrezno raziskovalno opremo. Klasična filologija mora imeti tudi svoje raziskovalno telo.

Inštitut: Seminar za klasično filologijo in antično zgodovino, fond 110, mapa 551-185

Osebje: Nikola Vulić; Vasilije Djerić; dr. Veselin Čajkanović; Rastislav Marić, docent; dr. Mihailo Petrović, docent.

\section{DOKUMENT ŠT. $2 \mathrm{~A}$}

Arhiv Jugoslavije, Beograd, fond št. 110, mapa št. 551

Srbski civilni načrt [1942]

Fond št. 110, mapa št. 551-180, inv. št. 1776

Srbski kulturni načrt, seznam problemov

Biološki sektor:

1. Boj proti tuberkulozi, malariji, tuberkulozi in veneričnim boleznim

2. Zaščita srbske krvi in zdravih potomcev

3. Zdravstvena svetovalnica za matere in otroke

4. Pravilna razporeditev bolnišnic in drugih zdravstvenih centrov po državi 
5. Pravilna razporeditev zdravnikov v družbi

6. Zdravstvena zaščita učiteljev in učencev $[\ldots]$

Duhovni sektor:

18. Geološke raziskave srbskega podeželja

19. Center za geografske raziskave srbskih pokrajin

20. Raziskave bioloških značilnosti prebivalstva vseh srbskih pokrajin

21. Izdelava rasnega zemljevida Srbije in ostalih srbskih pokrajin

22. Služba za podatke o vremenu

23. Klimatografija srbskih pokrajin s klimatskim atlasom

24. Klimatografija različnih vremenskih tipov

25. Seizmična preiskava naše države

26. Izdelava seizmične karte, spektra in pregleda seizmoloških obdobij

27. Center za raziskave srbskega jezika in njegove zgodovine

28. Slovar sodobnega srbskega jezika $\mathrm{v}$ znanstveni in poljudni izdaji

29. Dialektološki srbski slovar

30. Etimološki srbski slovar

31. Srbski jezikovni zemljevid

32. Predelan in razširjen Slovar srbske pisne preteklosti Djure Daničića

33. Slovnica in slovar stare srbščine

34. Izdelava zgodovine srbske književnosti

35. Izdelava srbske bibliografije

36. Zgodovina srbskega gledališča in standardni srbski repertoar

37. Center za raziskave srbskega ljudskega pesništva in ostalega ustnega izročila

38. Center za raziskave naše glasbene dediščine

39. Center za raziskave srbske zgodovine

40. Izdelava zgodovine srbskega naroda

41. Izdaja srbskih virov

42. Raziskave nekdanjih srbskih držav v predzgodovinski in klasični dobi

43. Odnosi med Srbi in Bizantinci

a) raziskave odnosov med rimsko kurijo in Srbi

b) odnosi med otomanskimi Turki in Srbi

c) raziskave odnosov med Slovenci in Srbi

44. Raziskave odnosov med Nemci in Srbi

45. Raziskave odnosov med državami na Apeninskem polotoku in Srbi

46. Raziskave odnosov med Srbi in sosednjimi državami

47. Raziskave odnosov med Srbi in carigrajskim patriarhatom

48. Raziskave o delu bolgarskega eksarhata

49. Center za raziskave etnične preteklosti in značilnosti srbskih pokrajin

50. Raziskave o preteklosti srbskih družin in posameznikov

51. Raziskave etničnih tipov srbskega prebivalstva

52. Opis narodne noše, značilne za posamezno srbsko pokrajino

53. Opis vsakdanjega življenja v posameznih srbskih pokrajinah 
54. Center za zgodovino srbske umetnosti in ohranitev starin

55. Inventar srbskih srednjeveških in novejših umetniških spomenikov

56. Popis arheoloških starin in nahajališč

57. Razvijanje sistematičnega pregleda zgodovine srbske umetnosti

58. Bibliografija umetnosti

59. Izdaja srbske ljudske umetnosti

6o. Poljudna enciklopedija

61. Razvoj splošne zgodovine

62. Razvoj splošne zgodovine književnosti

63. Razvoj splošne zgodovine umetnosti

64. Opisna bibliografija nacionalno pomembnih raziskav

65. Centralni katalog

66. Nacionalni knjižnični program

67. Nacionalni arhivski program

68. Nacionalni muzejski program

69. Vrste šol

70. Načrti in programi za vse vrste šol

71. Knjige za vse vrste šol

72. Ustrezna razporeditev šol v državi

73. Izkoreninjenje nepismenosti

74. Nacionalni založniški program

75. Najboljših sto knjig srbskih avtorjev

76. Ustanovitev splošnega pedagoškega inštituta

77. Inštitut za pravoslavno srbsko kulturo

78. Inštitut za primerjalne študije verstev

79. Družbena ustanova srbske Cerkve

8o. Popis in opis starodavnih srbskih rokopisov

81. Stare srbske tiskane knjige

82. Zgodovina srbske Cerkve

83. Življenjepis svetega Save

84. Viri za zgodovino srbske Cerkve

85. Izdaja srbskega Nomokanona (Krmčija) iz leta 1219

86. Izdaja Dušanovega zakonika

87. Izdaja zgodovinskih privilegijev srbskega ljudstva

88. Izdaja Kotorskega statuta

89. Izdaja korpusa dokumentov v srbski cirilici

90. Izdaja črnogorskega pravnega korpusa od 15. do 18. stoletja

91. Izdaja turških zakonov in odlokov od 15. do 19. stoletja

92. Material za pravno zgodovino od leta 1904 do 1941

93. Vprašanje pravnega jezika

94. Vzpostavitev pravnega izrazoslovja

95. Izdaja zgodovinskopravnega slovarja

96. Pravna bibliografija

97. Neodvisnost sodnikov in državnih tožilcev

98. Teritorialna razporeditev sodišč

99. Problem uradništva 
100. Reforma uprave

101. Reforma civilne zakonodaje

102. Inštitut za statistiko in demografijo

Ekonomski sektor:

103. Preskrba prebivalstva

104. Organizacija dela

105. Varnost in zavarovanje dela in delovnega prebivalstva

106. Varstvo proizvodnje

107. Varstvo prebivalstva

108. Notranja kolonizacija

109. Davčna reforma

110. Rehabilitacija javnih financ in uravnotežen proračun

[...]

Tehnični sektor:

140. Melioracija in izsuševanje močvirij

141. Nacionalna energetika

142. Nacionalizacija rudnikov

143. Gradnja cest

144. Dopolnitev železniškega omrežja

145. Elektrifikacija države

146. Industrializacija države

$[\ldots]$

Imenovane so bile komisije za naslednje probleme:

1. Izdelava srbskega antibarbarusa (filozofska)

2. Študija o nemških prizadevanjih za združitev vseh nemških dežel (glej 441)

3. Organizacija izdajanja del naših in tujih filozofov (filozofska)

4. Sto let civilnega zakonika princa Aleksandra Karadjodjevića za Kneževino Srbijo (pravna)

5. Študija medplemenskega prava v Črni Gori (pravna)

6. Sociološko-etnološka raziskava zločinskih nagnjenj v naši družbi

7. Izdaja zbirke mednarodnih pogodb (pravna)

8. Varnost sodnih arhivov (pravna)

9. Izbor kandidatov za študij prava (pravna)

[Dokumenti zbujajo vtis, da Čajkanović ni bil obtožen zaradi svojega filološkega dela. Kljub temu ostaja več vidikov, ki bi jih kazalo preučiti. Čajkanović je pisal o srbski religiji; knjige, ki zadevajo »opij za ljudstvo«, so bile po partijskem prevzemu oblasti prepovedane, če že ne uradno, pa v praksi. Čajkanovićev sin, prevajalec Nikola Čajkanović, je ostal do smrti prepričan, da je za očetovo preiskavo stal bodisi Dušan Nedeljković bodisi kdo drug, ki si je prizadeval prevzeti mesto oddelčnega predstojnika prek politično motivirane igre moči. Po drugi strani bi o preganjanju Čajkanovića lahko razmišljali 
tudi v luči partijskega »boja« proti »opoziciji« ali proti beograjski mestni eliti, zlasti proti intelektualcem.]

\section{DOKUMENT ŠT. 3}

Prepis pogovora $\mathrm{z}$ Nikolo Čajkanovićem, sinom ${ }^{17}$ Veselina Čajkanovića, opravljenega 5. marca 2002 (vključeni so samo relevantni odlomki)

[Veselin Čajkanović] se je rodil v Beogradu leta 1881, v uradniški družini. $\ldots$

V Beogradu je obiskoval šolo in gimnazijo (Beograjska prva gimnazija). Na njegovem sprejemnem izpitu je bil prisoten delegat, takšna je bila praksa, ne vem, ali je še tako. Delegati so bili profesorji z univerze, določeni za predsednike vpisne komisije. Njegov je bil Pavle Popović. Oče je opravil izvrstno. Nato je študiral klasično filologijo, tukaj v Beogradu. Na dan, ko je diplomiral, je pri vratih naletel na Pavleta Popovića, in čeprav se vse od vpisa nista videla, ga je Popović takoj prepoznal.

— »Kolega, kaj je novega? Že dolgo vas nisem videl.«

— »Pravkar sem diplomiral.»

— »Kaj boste zdaj?«

— »Poiskal si bom mesto na gimnaziji.»

- $\mathrm{O}$ ne, ne boste. Človek, kot ste vi, ne gre na gimnazijo. Dobili boste štipendijo.« To je bilo takrat zelo redko, mogoče jih je bilo v vsej Srbiji okrog petnajst. »V Nemčijo greste.«

Tako je šel oče v Nemčijo na dodatno izobraževanje, »suplementarni študij«, kar je bil takrat izraz za današnji podiplomski študij. Sprva je študiral pri profesorju Crusiusu, nato pa pri profesorju Krumbacherju v Münchnu, ki je v tistem času veljal za avtoriteto klasičnih študij in humanistike in je bil eden najboljših na svetu. Tam je diplomiral z odliko, končal svoj doktorat pri Krumbacherju z najvišjo oceno ter se vrnil v Beograd, kjer je s to izobrazbo takoj zasedel mesto docenta na beograjski univerzi. To je bilo leta 1908. [...]

Začel je torej kot docent. Nato so prišle vojne, v katerih je sodeloval kot rezervni častnik. Ne vem natančno, mislim, da je začel kot ... mogoče poročnik ali podporočnik, $v$ rezervi. $V$ turški vojni je bil na fronti v bitki pri Kumanovem in kasneje v Bitoli. Nato se je boril v prvi svetovni vojni in je v zadnjih dveh dneh ali ob koncu umika skozi Albanijo dobil davico. Premestili so ga v Bizerto, kjer je okreval.

17 Projekt Inštituta za balkanske študije in Dušana T. Batakovića, »Soočanje s totalitarno dediščino komunizma v Srbiji in Črni Gori«. Niz dokumentarnih oddaj »Rdeča doba [Crveno doba], ki je bil njegova posledica, je leta 2004 režiral Petar Jakonić; serija je dostopna na spletu. 
Ko si je nekoliko opomogel, vendar se še ni mogel vrniti na fronto - to je zelo zanimivo obdobje njegovega življenja - je ustanovil tiskarno ${ }^{18} \mathrm{za}_{\mathrm{srb}}$ ske invalide. Skupaj z nekim francoskim častnikom sta tiskala časnike za srbske vojake in izdajala majhno knjižno zbirko, morda je izšlo okrog dvajset knjig. ${ }^{19}$ Za to zbirko je veliko pisal tudi sam. Pisal je o naših rečeh in o svoji stroki, o srbskem verstvu in bajeslovju, napisal je tudi priročnik za francoščino ${ }^{20}$ in francosko-srbski slovar ${ }^{21}$ za naše vojake, ki so bili tam.

Tik pred koncem ga poveljstvo ni hotelo poslati nazaj. Mislim, da mu je bilo žal in da se je počutil zelo krivega. Niso ga hoteli poslati nazaj, ker so potrebovali nekoga, da gre na tuje in pokaže, kaj je Srbija in kdo so pravzaprav Srbi. Vojna je bila že pri koncu, zato ne bi bil kaj prida koristen, toda tako je hotelo poveljstvo. Nekaj časa je bil v Parizu, malo v Londonu, kjer je sodeloval v tako imenovani srbski propagandi. Obenem je vsak trenutek prostega časa izkoristil za delo v Bibliothèque nationale v Parizu ter v British Museum Library v Londonu.

Nato se je vrnil in nadaljeval svoje delo kot profesor. Takoj zatem, leta 1919, ko je že postal docent, mislim da ... oprostite, docent je že bil, postal je izredni, okrog leta 1922 pa redni profesor na beograjski univerzi; za klasične jezike, grško in rimsko književnost, njegova glavna dela pa so bila o zgodovini verstev. Kmalu zatem, ne vem, katerega leta, je nastopil kot profesor klasične filologije. Nemudoma je dobil profesuro na Teološki fakulteti kot nadomestni profesor za zgodovino verstev, množina, to je bila zgodovina nekrščanskih verstev. Tam je predaval, mislim da okrog trideset let, sedemintrideset let pa je poučeval klasično filologijo na beograjski univerzi. [...]

Bil je tudi dekan. Izvoljen je bil trikrat ... v tridesetih letih. Leta 1931, 1932 in 1933, se mi zdi. Nato je leta 1941 spet postal dekan, vendar je takrat prišlo do velike zmede. Pravzaprav je bil izvoljen za dekana, a se je opravičil in zavrnil položaj, ker ni hotel biti dekan. Dva ali tri dni kasneje se je ponovila stvar izpred dveh let, ko je dekane začel imenovati minister za šolstvo. Iz časopisja je izvedel, da je bil imenovan za dekana. Čajkanovića so celo obtožili, da je med okupacijo skušal s silo zasesti ta položaj, kot bi bilo to zanj neke vrste napredovanje in kot bi ne bil dekan že trikrat poprej. [...]

18 Avaunt = En avant [Poročila iz poveljstva rezervnih enot in častniških šol] 1, št. 1, 28. februar, 1916 - 3, št. 872, 16. december, 1918, Bizerta, Tunizija.

19 Glej denimo Veselin Čajkanović, Iz stare zakladnice, nedeljska priloga Avaunt (Bizerta, 1917), 4; idem, Poroka Maksima Crnojevića: srbska ljudska pesem s komentarjem (Bizerta, 1917), 55 strani; Albert Aufort in Veselin Čajkanović, A l'Hôpital: guide de conversation français-serbe (Bizerta, 1918), 167 strani; Veselin Čajkanović, Srbske ljudske pesmi 2, bajeslovne pesmi (Bizerta, 1918), 232 strani; idem, predgovor k delu Stara srbska religija in mitologija: članki iz slovarja in zbirke pregovorov Vuka Stefanovića Karadžića (Bizerta, 1918), 216 strani; Titus Maccius Plautus, Aulularia in Menaechmi, prevedel Veselin Čajkanović (Bizerta, 1918), 104 strani; Veselin Čajkanović, Srbski bralec za začetnike, druga izdaja (Bizerta, 1918), 128 strani.

20 Albert Aufort in Veselin Čajkanović, Izvleček iz francoske slovnice in francoske konverzacije (Bizerta, 1916), 144 strani.

21 Albert Aufort in Veselin Čajkanović, Francosko-srbski slovar (Bizerta, 1917), 148 strani. 
Leta 1944 se je na beograjski univerzi oblikovalo nekakšno častno razsodišče, kjer je moral dati vsak profesor izjavo o tem, kaj je počel; poslali so okrožnico, te okrožnice se še spomnim, po njej si moral predložiti informacije o vsem, kar si počel med okupacijo - ter poročati tudi o vsem, kar so počeli tvoji kolegi [...] To okrožnico so med drugimi poslali pokojnemu profesorju Zadjini na Tehniški fakulteti, kasnejši Fakulteti za gradbeništvo. Rekel je: »Glej glej, zdaj bom dobil še medaljo Denunciate, " to je bila seveda aluzija na znano italijansko medaljo, imenovano Annunziata. Potem se je sestalo razsodišče, čeprav niso mogli najti ničesar. Nato so vsi dokumenti, s katerimi se je oče branil in ki so dokazovali njegovo nedolžnost, izginili iz arhiva Filozofske fakultete, njega pa so odstranili z univerze. Bil je preprosto odpuščen, kot da ne bi nikoli obstajal. Naslednjega dne, potem ko je od univerze prejel obvestilo, da je odpuščen, je padel v posteljo. Štirinajst mesecev je bil bolan. Nikoli več ni vstal. Ta stvar ga je seveda popolnoma sesula. Verjetno je imel kaj latentnega; umrl je zaradi raka, verjetno je bil latentni rak; toda kot so kasneje dejali vsi zdravniki — da, lahko je latenten, toda ko pride takšen udarec, ko se zgodi nekaj tako stresnega, se rak nemudoma prebudi. [...]

Na univerzi je bil pritisk, seveda; nekateri so se izpostavljali, da bi dobili položaj, nekaj pritiska je bilo tudi od zunaj. Slišal sem, ne vem koliko je v tem resnice, verjetno veliko, da so se nekateri profesorji resno pritoževali, zlasti o ravnanju z mojim očetom. Potem je Državna komisija za zločine okupatorjev in njihovih sodelavcev s predsednikom komisije Dušanom Nedeljkovićem izdala obtožnico za, ne spomnim se točno, recimo za petnajst vplivnih imen $z$ beograjske univerze, češ da so škodovali srbski narodni časti, ker so sodelovali pri tako imenovanem civilnem načrtu. Civilni načrt je bil nekakšen načrt med okupacijo, ustvarjen preprosto zato, da bi se nekaj počelo, da bi preusmerjal pozornost. Naj vam povem, kaj je bil največji dosežek tega načrta. Spremenili so ime dveh oddelkov na Filozofski fakulteti. Takrat, pred vojno in na začetku vojne, sta obstajala zgodovinsko-filološki oddelek in naravoslovno-znanstveni oddelek. Največji dosežek civilnega načrta je bil menda to, da so ju preimenovali v filološko-zgodovinski in znanstveno-naravoslovni oddelek. Mislite si lahko, kakšen je bil videti ta načrt. Poleg tega moj oče niti v tem položaju ni bil navdušen nad sodelovanjem pri tem načrtu. Iz obvestila je izvedel, da so ga imenovali za pomočnika pri civilnem načrtu, in to je bilo vse. [...]

Poleg tega lahko povem, da je bil v težjem položaju kot ostali. Veste, kako je bilo takrat, moral si pokazati, da se je zgodovina Srbije začela 7. julija 1941 [uradni začetek vstaje pod vodstvom komunistov], medtem ko je oče v svojih knjigah ugotavljal, da so imeli Srbi nekakšno kulturno življenje, da se je nekaj dogajalo že več stoletij pred tem. Nekdo je podobno zapisal v članku ob izidu njegovih izbranih del v petih knjigah — da je za spomin na srbsko omiko storil več kot Homer za Grčijo, saj je imel Homer obilo snovi, oče pa ničesar. Začeti je moral iz nič, pa je vendar raziskal to kulturo. Pravijo, da se 
je za njegov položaj na oddelku zlasti zanimala neka ženska, ki je bila dobra prijateljica Dušana Nedeljkovića. Jasno je bilo, da je moral oditi, saj je imela za ta položaj v primerjavi z mojim očetom ravno toliko možnosti kot jaz za položaj primabalerine v primerjavi z Ašhen Ataljanc.

Prevedel Blaž Strmole 